See discussions, stats, and author profiles for this publication at: https://www.researchgate.net/publication/350948928

\title{
Specific Learning Disability Identification Practices in the U.S.A: A Survey of Special Education Administrators
}

Article · April 2021

DOI: $10.1007 / 540688-021-00375-4$

CITATIONS

0

4 authors:

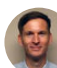

Adam Lockwood

Kent State University

16 PUBLICATIONS 74 CITATIONS

SEE PROFILE

Karen A. Sealander

Northern Arizona University

23 PUBLICATIONS 163 CITATIONS

SEE PROFILE

Some of the authors of this publication are also working on these related projects:

Project Assessment Science View project

Project Meta Science \& Open Science in School Psychology View project
READS

294

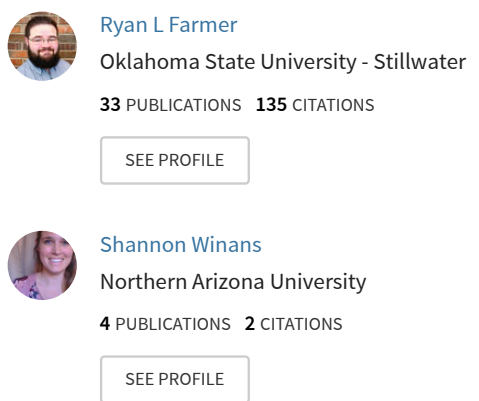


Specific Learning Disability Identification Practices in the U.S.A: A Survey of Special Education

\author{
Administrators \\ Adam B. Lockwood \\ Kent State University \\ Ryan L. Farmer \\ Oklahoma State University \\ Karen Sealander \\ Shannon Winans \\ Northern Arizona University
}

Author Note

This is a preprint of an article published in Contemporary School Psychology. The final authenticated version is available online at: at DOI:10.1007/s40688-021-00375-4. This manuscript (04/17/2021) is not the final version and may differ from the final, published version. The authors declare that they have no conflict of interest. We wish to thank all of the administrators who completed this survey and who work tirelessly to serve students in their districts. Correspondences concerning this article should be addressed to Adam Lockwood, Kent State University. Email: alockwo2@kent.edu 


\begin{abstract}
Specific learning disorder (SLD) identification is arguably one of the most significant controversies in school psychology. One component of this issue is that guidelines and practices vary substantially across professionals and states, which leads to inconsistent identification rates and outcomes for students. To assess the extent of this problem at the district level, we surveyed special education administrators from 725 U.S. school districts regarding their districts' current specific learning disability (SLD) identification practices in the United States. Significant differences in SLD identification methods were reported across districts. Significant differences in SLD identification methods were also found across regions and between districts that used different educators to collect academic achievement test data. Curriculum based measures were also used more frequently in districts that identify SLD using Response to Intervention. Implications of these findings for policy and for practice are considered.
\end{abstract}

Keywords: specific learning disability, identification methods, eligibility 


\section{Specific Learning Disability Identification Practices in the U.S.A: A Survey of Special Education Administrators}

Specific Learning Disability (SLD) is the largest eligibility category within the Individuals with Disabilities Education Improvement Act ([IDEA], 2004), representing more than a third of all special education students during the 2017-2018 school year (National Center for Education Statistics [NCES], 2019). SLD is described in IDEA as a disorder related to an individual's psychological processes that leads to unexpected underachievement in one or more of following areas: oral expression, listening comprehension, written expression, basic reading skills, reading fluency, reading comprehension, mathematics calculation, mathematics problem solving. There is no universally accepted model for understanding SLD, nor a gold-standard method for identification (Fletcher \& Miciak, 2019). Misclassification of an SLD can have long term negative consequences that can follow students throughout their lives (Higgins, et al., 2002), may lead to underperformance due to self-fulfilling prophecies (Gentrup et al., 2020) or lack of appropriate services and instruction (Fletcher, 2012). Furthermore, different SLD identification methods lead to varying rates of student identification (Maki et al., 2017). Due to the high-stakes nature of SLD classification and the absence of an agreed upon method for identifying SLD, continued research into current practices in the identification of SLD is needed. This current research attempts to examine current SLD identification methods across U.S. school districts to identify the factors that influence method use.

\section{SLD Frameworks}

While federal law defines eligibility in broad terms, various SLD identification methods exist, including the Ability-Achievement Discrepancy (AAD), Pattern of Strengths and Weaknesses (PSW), and Response to Intervention (RtI) model (Maki et al., 2015). However, key 
to all methods of SLD identification is the presence of unexpected underachievement (Fletcher \& Miciak, 2019). AAD, the first general framework for understanding unexpected underachievement, was codified in the Education of All Handicapped Children Act of 1975. AAD operationalizes unexpected underachievement as a significant discrepancy between overall cognitive ability and a specific area of academic achievement as measured by norm-referenced academic achievement tests (Fletcher \& Miciak, 2019; Lichtenstein, 2014; Maki \& Adams, 2018). While this method has been in use for decades, it has been criticized for having issues related to reliability (Barnett \& Macmann, 1992; Francis et al., 2005; Maki \& Adams, 2020 and a lack of instructional relevance (Burns et al., 2015; Vaughn \& Fuchs, 2003).

A second set of methods based upon the cognitive discrepancy framework are those associated with the PSW models (e.g., Dual Discrepancy/Consistency model; Flanagan, et al., 2013). Like the AAD model, PSW methods require a discrepancy between standardized scores of cognitive ability and academic achievement, with the addition of a corresponding neuropsychological processing deficit that explains the underachievement (Fletcher \& Miciak, 2019). Despite significant differences between these methods, one commonality is that both PSW and AAD generally use norm-referenced, standardized tests of cognitive ability and academic achievement in order to make an identification (Flanagan \& Alfonso, 2018). While PSW is a relatively new adaptation of cognitive profile analysis, there is a significant amount of evidence that suggests it is not effective for SLD identification due to issues related to reliability and validity (Kranzler, et al., 2016; Maki \& Adams, 2020; Miciak et al., 2014; Miciak et al., 2016; Miciak et al., 2015; Stuebing et al., 2012), and like AAD, that the process lacks instructional relevance (Burns et al., 2015; Maki \& Adams, 2020). 
In contrast to the cognitive discrepancy framework utilized in AAD and PSW, the instructional framework identification methods based on RtI posit that unexpected underachievement is documented as inadequate instructional response to intensive evidencebased interventions (Miciak \& Fletcher, 2019; Vellutino et al., 2006). In a RtI framework, students are provided with research-based interventions of increasing intensity and their progress is monitored frequently to assess whether those interventions have produced a desired change in academic outcomes. While there is no universally agreed upon method for identification of SLD using RtI, a failure to respond to adequate interventions is a key component to all RtI approaches. Progress monitoring during RtI is typically conducted using curriculum-based measurements (CBMs) and assessment of cognitive ability is not required (Maki et al., 2015; Miciak \& Fletcher, 2019). Like AAD and PSW, RtI has been criticized as being an unreliable approach to SLD identification (Brown Waesche et al., 2011; Maki et al., 2015, though one recent study by Maki and Adams (2018) suggested that RtI may be the most consistent of these approaches. Additionally, by the very nature of the assessment of curriculum, RtI is highly relevant to instruction.

\section{Method Use}

Several studies have examined the use of these SLD identification methods. For example, Maki et al. (2015) examined state regulations regarding the use of AAD, PSW, and RtI following the reauthorization of IDEA (2004). They found that AAD was allowed in $67 \%$ of states while PSW was allowed in $27 \%$ of states for the identification of SLD. According to the Maki et. al. study, RtI was the sole method used in $16 \%$ of states, was allowed in combination with other methods in $17 \%$ of states and allowed "as required by IDEA" (p. 462) in the remaining states. Maki et al. also found that $20 \%$ of states explicitly prohibited the use of AAD while another $13 \%$ 
did not specify whether or not this method could be used. Additionally, Maki and colleagues indicated that roughly half of states prohibited the use of PSW while $24 \%$ did not specify whether this method may be used. Of note, Maki and colleagues did not specify which states use or allow each method. Benson et al. (2020) also examined SLD identification regulations by state and noted that 35 states and Washington DC allowed the use of AAD, 18 states allowed the use of PSW, nine states required RtI in isolation (seven states require RtI in isolation for all grades), and seven required RtI in combination with one of the other two approaches. In sum, these studies suggest that SLD identification guidelines vary significantly across states and are often vague or non-existent. Neither of these studies explored practices at the district level.

Several studies have also examined the reported use of SLD methods by school psychologists. In their survey of 471 school psychologists, Cottrell and Barrett (2016) also found opaque results. These authors discovered that $\mathrm{AAD}$ was required by approximately $30 \%$ of participants' schools, RtI by $24 \%$, and only $9 \%$ required PSW. Cottrell and Barrett also found that $26 \%$ disallowed AAD, 24\% disallowed RtI, and that 48\% disallowed PSW for the determination of SLD eligibility. Additionally, these researchers found that schools in the South were less likely to require or allow AAD then Midwestern schools and that Southern schools were more likely to require or allow PSW compared to Western schools. No differences in the use of RtI between regions were noted. However, there were several limitations of this study. First, only nine participants were from the Northeast and therefore no comparisons were made for this region which comprised 16\% of the student population in 2015 (NCES, 2017). Also, nested data were gathered (i.e., multiple participants were recruited from the same district), but the data was treated as independent in an ANOVA, which may have led to inflated risks for Type 
I and II errors (Scariano \& Davenport, 1987) and does not allow for interpretation at the district level.

More recently, Maki and Adams (2018) surveyed 461 school psychologists and found that roughly a third of practitioners indicated primarily using each of the three methods (i.e., $35 \%$ used PSW, 35\% used RtI, and 30\% used AAD). Additionally, Benson and colleagues (2020) surveyed 1,317 school psychologists and found that 53\% of participants reported using PSW, 51\% RtI, and 37\% used AAD. Benson et al. noted that many participants used multiple SLD identification frameworks but acknowledged that it is unclear whether these different methods are used in concert or separately depending on the particular student. Also, of note, all of these studies focused solely on school psychologists and did not gather information on practices across professionals (e.g., special education teachers, educational diagnosticians). Furthermore, neither study reported the extent to which different states or geographic regions were represented and did not collect data on a district level.

In summary, several studies have sought to describe the SLD identification practices of school psychologists in general and of state guidelines specifically regarding SLD (e.g., Benson et al., 2019; Benson et al., 2020; Cottrell \& Barrett, 2016; Maki \& Adams, 2018). However, no studies have (a) examined practices from the perspective of special education administrators nor have they (b) examined practices at the district level. To understand the complexity of practice in the field, it is important to obtain data at the district level and the perspective of multiple stakeholders. Regarding the first of these claims, a recent survey of 725 special education administrators found that school psychologists only conduct the norm-referenced tests of academic achievement used in AAD and PSW frameworks between 43-50\% of the time and that they almost never administer the CBMs used in an RtI framework (Lockwood et al., 2021). As a 
result, focusing primarily on the perspectives and practices of school psychologists may skew the overall perspective of SLD practices in general. For instance, certain states (e.g., Louisiana) do not generally include school psychologist in the evaluation of SLD (Louisiana Department of Education, 2009) and other states (e.g., Texas) do not require their inclusion in the process, instead largely relying on educational diagnosticians (Schultz \& Stephens, 2015). Additionally, focusing on state-level guidelines potentially ignores heterogeneity within states.

\section{Current Study}

The purpose of this study was to expand upon the current research base by examining special education SLD identification practices (a) at the district level (b) as reported by special education administrators across the U.S. and (c) across professionals. Thus far research has focused solely on the practices and perspective of school psychologists (e.g., Benson et al., 2019; Benson et al., 2020; Cottrell \& Barrett, 2016; Maki \& Adams, 2018), though survey research suggests that school psychologists are not solely responsible for testing when it comes to SLD identification (Lockwood et al., 2021). As there is a shortage of school psychologists, especially in rural areas (National Association of School Psychologists, 2017) and Western states (American Association for Employment in Education, 2016), an additional purpose of this study was also to determine if locale (i.e., rural vs urban), geographic area, and the inclusion of school psychologists in academic achievement data collection impacted which SLD identification method was used. Additionally, we wanted to gather a sample that was representative of school districts geographically and without the possibility of multiple participants per district.

Furthermore, as CBMs are generally used within an RtI framework, we hoped to determine if CBM use was associated with SLD identification method. Specifically, we hoped to answer the following questions at the district level across states: 
1. What methods of SLD identification are currently being used across professions?

2. Do SLD identification methods vary depending on:
a. Region?
b. Locale?
c. Profession of primary academic achievement tester?
d. CBM use?

\section{Method}

This data was gathered as part of a larger survey of district special education eligibility and assessment practices. The study was approved by the lead author's Institutional Review Board. Participation was voluntary and consent was provided electronically. It is important to note that as part of the larger study, in addition to demographic questions, participants were asked: a) whom in their district "administers the majority of academic achievement tests used for initial special education eligibility determinations," b) whether their district uses "standardized curriculum-based measures (e.g., AIMsweb, DIBELS, EasyCBM, edcheckup, Yearly ProgressPro, FastBridge Learning)," c) their district locale and d) their state, as these variables are used in this current study. Additionally, to ascertain the SLD identification method used, all participants were asked "In your district, what is the primary method of determining a specific learning disability (SLD)?” and were allowed to select one option only.

\section{Participants}

Participants included 725 special education administrators from 48 states. Administrators were chosen for this study for several reasons: a) we wanted to gather data regarding practices across professions (not just school psychologists), b) recent research (i.e., Boccio, 2016; Cottrell and Barrett, 2016) has suggested that administrators often dictate the eligibility methods and 
assessment practices used and c) they have insight into special education practices in their district across professions (Lockwood et al., 2021). Participants were largely were Caucasian, $(88 \%)$, female (80\%), and held a title of Director of Special Education or the equivalent (92\%; e.g., director of student support services). Data regarding education level, age, and years working in education can be found in Table 1.

\section{Participant Recruitment}

A link to our survey was emailed to a special education administrator from each U.S. districts with 3000 or greater students during the 2018-2019 school year. This inclusion cutoff criterion was chosen as we wanted to gather data about the majority of students served in the United States without the hardship of soliciting participation from the over 18,000 school districts listed on the NCES website that year (2020). Sampling school districts with 3000 or more students is good compromise (Levenson, 2012) as more than $70 \%$ of U.S. children are served in districts of this size. Based on this criterion, a survey recruitment link was emailed to 3,401 participants between April and May 2019. In total three participation email requests were sent per district. Seven-hundred twenty-five participants representing $21.3 \%$ of contacted districts completed the survey.

\section{Survey Design}

The survey consisted of 37 items designed to assess district-level SLD identification methods and assessment practices. Skip logic was used to limit response time. Survey items were generated based on recent peer-reviewed articles (e.g., Maki et al., 2015). The survey was reviewed by nine content experts (i.e., with expertise in academic assessment or special education administration). Revisions, deletions and additions to survey items were made based on their feedback. The questionnaire was administered using Qualtrics, an online survey software 
platform. A PDF version of the full survey is available at https://osf.io/wcuvz/ and is open access.

\section{Analysis}

Data were downloaded from Qualtrics and imported to SPSS v. 25 for analysis.

Descriptive statistics were calculated to answer question one. A series of chi-square tests were used to answer question two. States were coded into U.S. Census Bureau regions to allow for meaningful analysis. Post-hoc analyses using adjusted residuals were used to determine the contribution of each cell to the statistically significant findings. Because multiple post-hoc analyses were conducted, the criteria of Garcia-Perez and Nunez-Anton (2003) was used to control for family-wise error. Specifically, significance values for region and profession were set at $.0025(.05 / 20)$, and at $.005(.05 / 10)$ for CBM use.

\section{Results}

\section{Current Methods of SLD Identification}

To determine how well the sample generalized to the U.S. student population geographically, a one-sample chi-square test was calculated. Results indicated that the sample proportion of participants was not significantly different than the projected student population for Fall 2020 as reported by NCES (2020), suggesting that participants were proportionate to the students served $\left(\chi^{2}(\mathrm{df}=3)=2.66, \mathrm{p}=.45\right)$. Participants were asked to indicate the primary method of identifying a SLD. They indicated that norm-referenced tests, both academic achievement and cognitive, continue to be heavily relied upon for the identification of SLD. The AAD (referred to as simply "discrepancy model" in the survey) appears to continue to be the most relied upon method used by $29 \%$ of participant districts. This method was followed by PSW (20\%), RtI only (19\%), a combination of RtI and AAD (15\%), and a combination of RtI 
and PSW (15\%). Roughly $1 \%$ of participants indicated that they used another method (e.g., AAD and PSW). State-by-state responses varied greatly as did within state data. Upon examining states with 10 or more participants, the use of AAD in isolation for SLD identification varied from $88 \%$ (Pennsylvania) to 5\% (Ohio), the use of PSW in isolation ranged from $82 \%$ (Michigan and Texas) to $2 \%$ (Pennsylvania), and the use of RtI in isolation varied from $100 \%$ (Wisconsin) to $1.7 \%$ (California). Hybrid models also varied greatly with RtI and AAD ranging from 56\% (Georgia) to 5\% (California) and RtI and PSW ranging from 60\% (Connecticut) to 2\% (California). For states with more than one response, only participants in Delaware, New Hampshire, and Wisconsin reported using the same identification method in all sampled districts. Additionally, at least one participant from 27 states indicated the use of AAD in isolation, at least one participant from 23 states indicated PSW in isolation, at least one respondent from 31 states indicated the use of RtI in isolation, at least one participant from 29 states reported RtI and AAD, and at least one respondent from 30 states indicated RtI and PSW. State-by-state SLD information is provided https://osf.io/wcuvz/, though this data should be interpreted with extreme caution due to the low sample sizes per states.

\section{Differences in SLD Identification}

Chi-square statistics suggested that there were significant differences in SLD identification methods across regions $\left(\chi^{2}(12, \mathrm{~N}=713)=100.01, p<.001\right.$, Cramer's $\left.V=.216\right)$ and across professionals responsible for academic achievement testing $\left(\chi^{2}(12, \mathrm{~N}=712)=94.21\right.$, $p<.001$, Cramer's $V=.210)$ but not across locales $\left(\chi^{2}(16, \mathrm{~N}=710)=13.09, p=.67\right.$, Cramer's $V=.067)$. Post hoc analyses indicated that AAD was significantly more likely to be used in Western and Northeastern states and significantly less likely in Midwestern and Southern regions. AAD was also significantly more likely to be used in districts that relied on special 
education teachers to administer tests of academic achievement. RtI was significantly less likely to be used in Western states and more likely in Midwestern States. RtI was significantly more likely in districts that relied on school psychologists to administer tests of academic achievement. A PSW approach was significantly more likely in Southern states and was significantly less likely in the Northeastern region. A PSW approach was significantly more likely in districts that used educational diagnosticians and significantly less likely in districts that used special education teachers to administer tests of academic achievement. Additionally, a combination of RTI and AAD was significantly more likely in districts that use educational diagnosticians to administer tests of academic achievement. More detailed information can be found in Tables 2-4.

Districts were also asked to indicate whether they administer curriculum-based measures. Results indicated that there were significant differences in SLD identification methods depending on their use $\left(\chi^{2}(4, \mathrm{~N}=694)=15.464, p<.005\right.$, Cramer's $\left.V=.149\right)$. CBM was significantly more likely to be used in districts that relied on RtI as their identification method and significantly less likely in districts that used PSW. More detailed information can be found in Table 5.

\section{Discussion}

SLD is the most common disability category for special education eligibility in schools. However, state regulations for identifying SLD are inconsistent (Benson et al., 2020; Maki et al., 2015). Additionally, state identification guidelines greatly predict assessment practice in public schools (Benson et al., 2020). Given the influence of state identification guidelines and inconsistencies between states, this suggests great inconsistencies in identification practices between states. Thus, it is conceivable that a child may be found eligible for special education services under SLD in one state, but not when crossing the border into an adjacent state. 
Moreover, federal and state laws may be interpreted differently by various school districts. The purpose of this study was to better understand SLD identification practices at the district level and determine what variables may influence which methods are used. By better understanding current practices in school districts throughout the United States, we hope to inform policy and practice regarding the identification of SLD.

According to our results, the number of sampled districts that primarily use AAD in isolation is $29 \%$. These data suggest that AAD continues to be frequently used as the sole method for identifying an SLD. RtI and PSW appear to be used less frequently in isolation (both roughly $20 \%$ ) though RtI is used in combination with AAD and PSW in roughly $30 \%$ of districts (15\% and 15\%, respectfully). These data differ considerably from Maki and Adams' (2018) study, which suggested that each method is used equally. Our data also differed from the results of Benson et al. (2020), which suggested that PSW is used 53\% of the time followed by RTI (51\%) and then $\mathrm{AAD}(37 \%)$. While it is not entirely clear why our results differed from these previous studies, one probable explanation is that we provided the option for alternative responses (e.g., hybrid methods). Additionally, we sought out the perspective of one special education administrator per district rather than school psychologists as a whole. The latter approach likely sampled multiple school psychologists from some districts and did not represent practices of other professionals (e.g., educational diagnosticians) that are key in the determination of SLD identification and may use different methods than school psychologists. As such, these data may be answering slightly different, though related, questions.

Demographic regions appear to impact which approach will be used. Identification using RtI was most prevalent in the Midwest, though, even here, less than a third of participants reported that this method is used in isolation. RtI was especially underused in Western states 
with less than one in ten participants in this region reporting its sole use. These findings differ from Cottrell and Barret (2016) who found no differences across demographic regions in the use of RtI for SLD identification. AAD was very prevalent in Western states where it was endorsed by more than half of participants. AAD was not nearly as prevalent in the Midwest and South where it was used by roughly $18 \%$ and $21 \%$, respectively. Of note, this was also different than Cottrell and Barrett's study which found that school psychologists in the South were less likely to use this method but only when compared to Midwestern school psychologists. We also found that PSW was more prevalent in Southern states and used by $28 \%$ of districts and less prevalent in Northeastern states (used by only $6 \%$ of districts). This finding was somewhat in line with Cottrell and Barrett's study which found that Southern school districts required or allowed the use of PSW significantly more than Western schools.

The disparities between our findings and Cottrell and Barrett's (2016) may have been methodological as these researchers used a series of ANOVAs and had a much less stringent criterion for clinical significance $(p<.05)$, while we used chi-square statistics with $p$ values of .005 and .0025 . Also, due to their limited sample from the Northeast they were unable to make comparisons from this large region. These differences may also be due in part to how our study was framed as we focused on the primary method used, while these researchers focused on what was required and allowed. These differences may also have been impacted by our inclusion of hybrid methods (e.g., RtI and PSW) that provided a more nuanced picture of SLD identification. Additionally, these inconsistencies may have been influenced by the fact that we surveyed administrators and their participants were school psychologists. As noted earlier, several Southern states (e.g., Louisiana, Texas) rely heavily on educational diagnosticians (Lockwood et al., 2021). As we intentionally sampled one special education administrator per district 
minimizing the risk of sampling multiple persons from within the same district, we believe these data provide a more reasonable estimate of policies across districts.

We also found differences in SLD method based on whom was responsible for conducting academic achievement testing. RtI was more prevalent in districts relying on school psychologist, endorsed by approximately a quarter of these districts. AAD was more prevalent in districts that used special education teachers as test administrator and was used in close to $40 \%$ of these districts. PSW was more prevalent in districts that relied on educational diagnosticians, used by approximately half of these districts. Districts that used special education teachers tended to shy away from PSW, using it in slightly more than one in ten of these districts.

No differences in SLD identification method were noted across locales suggesting that SLD identification is impacted by region and professionals who collect academic achievement data regardless of whether the school is rural, urban or suburban. Not surprisingly, the RtI identification model was significantly more likely in districts that use standardized CBMs as these measures are generally used in this identification framework. As these measures were used in roughly $91 \%$ of these districts, it does suggest that close to one in ten districts that use an RTI identification method do so using non-standardized measures. Interestingly, only districts that used PSW were significantly less likely to use standardized CBMs, though they still did so in more than three fourths of these districts. This suggests that most districts use standardized CBMs regardless of the SLD identification method they use.

In sum, significant variation in SLD identification methods were reported between regions and professionals. Perhaps more troubling, the use of different methods ranged significantly across districts; for states with more than one response, only three states reported using the same identification method in all sampled districts. These results are fairly consistent 
with the previous research (e.g., Benson et al. 2020; Maki \& Adams, 2018; Maki et al., 2015), which suggests limited consensus regarding what SLD method should be used. As such, we can conclude that not only could a student be identified inconsistently between states, but a student may be identified inconsistently between districts within the same state. Even more surprising, participants from eight states indicated that their districts used SLD identification methods that Benson et al. (2020) noted were not allowed in their respective states. Most noticeably, of the seven states that require RtI in isolation for all grades, only participants in Wisconsin reported this consistently. This apparent disregard for state guidelines is likely underestimated due to the small sample sizes we obtained from many states; nevertheless, the data indicated cognitive testing persists even in states that prohibit its use for the identification of SLD. However, due to the small sample sizes obtained from many states, it is hard to say with any certainty how practices vary within any specific states with the exception of the larger states such as California.

\section{Limitations \& Future Directions}

This survey relied on self-report, which is always prone to bias due to social desirability, recall and measurement error (e.g., the items are not clear to participants; Althubaiti, 2016). For this reason, future research should consider examining SLD evaluation reports or other permanent products (e.g., district policy guidance or actual eligibility reports) to determine which methods are used across districts. As our survey focused on districts with 3000 or more students, the results may not generalize to smaller districts. Future research may wish to target small districts and standalone school districts such as charter schools to gain an understanding of SLD identification methods in these settings.

\section{Implications for Practice and Policy}


Our data suggested that questionable methods for the identification of SLD, most notably (though not exclusively) the use of AAD (Benson et al., 2020; Francis et al., 2005), continue. This is in part because there is no consensus regarding which method is defensible and therefore districts are depending on methods that rely on instructionally irrelevant tests (i.e., tests of cognitive ability; Burns et al, 2015) that lead to unreliable identification (Maki et al., 2017). Relatedly, while most districts report administering standardized CBMs, roughly half indicated that they do not use this data in the majority of SLD determinations. Districts that engage in AAD or PSW are highly encouraged to shift to a hybrid model that incorporates RtI data into their SLD identification method. Finally, as previously noted, identification methods vary greatly between districts. This lack of consistency may prove problematic for students relocating from one district to another as they may lose services simply by moving a few miles away. To address the use of problematic practices and inconsistency in determination methods, it would appear necessary to adopt uniform SLD identification criteria across the U.S. or at least within individual states.

\section{Conclusion}

SLD identification is an important process. Failing to accurately identify a student with a SLD can lead to denial of services, stigmatization, and lost instructional time. Despite the centrality of identification practices to education, as well as the repercussions of inaccurate identification practices, there is no consensus and great variability in SLD identification methods across the country and even within states. This appears to be true even in some states that have clear guidelines that do not allow for variation. 


\section{References}

Althubaiti, A. (2016). Information bias in health research: definition, pitfalls, and adjustment methods. Journal of Multidisciplinary Healthcare, 9, 211. https://doi.org/10.2147/JMDH.S104807

American Association for Employment in Education (AAEE). (2016). Educator supply and demand report 2015-2016: executive summary. AAEE.

Barnett, D. W., \& Macmann, G. M. (1992). Aptitude-achievement discrepancy scores: Accuracy in analysis misdirected. School Psychology Review, 21, 494-508. https://doi.org/10.1080/02796015.1992.12085631

Benson, N. F., Floyd, R. G., Kranzler, J. H., Eckert, T. L., Fefer, S. A., \& Morgan, G. B. (2019). Test use and assessment practices of school psychologists in the United States: Findings from the 2017 national survey. Journal of School Psychology, 72, 29-48. https/doi.org/10.1016/j.jsp.2018.12.004

Benson, N.F., Maki, K.E., Floyd, R.G., Eckert, T.L., Kranzler, J.H. \& Fefer, S.A. (2020). A national survey of school psychologists' practices in identifying specific learning Disabilities. School Psychology. https/doi: 10.1037/spq0000344

Boccio, D. E., Weisz, G., \& Lefkowitz, R. (2016). Administrative pressure to practice unethically and burnout within the profession of school psychology. Psychology in the Schools, 53(6), 659-672.

Brown Waesche, J. S., Schatschneider, C., Maner, J. K., Ahmed, Y., \& Wagner, R. K. (2011). Examining agreement and longitudinal stability among traditional and RTI-based definitions of reading disability using the affected-status agreement statistic. Journal of Learning Disabilities, 44, 296-307. doi:10.1177/0022219410392048 
Burns, M. K., Petersen-Brown, S., Haegele, K., Rodriguez, M., Schmitt, B., Cooper, M., Clayton, K., Hutcheson, S., Conner, C., Hosp, J., \& VanDerHeyden, A. M. (2015). Metaanalysis of academic interventions derived from neuropsychological data. School Psychology Quarterly, 31(1), 28-42. https://doi.org/10.1037/spq0000117

Cottrell, J. M., \& Barrett, C. A. (2016). Defining the undefinable: Operationalization of methods to identify specific learning disabilities among practicing school psychologists. Psychology in the Schools, 53(2), 143-157. https://doi.org/10.1002/pits.21892

Education of All Handicapped Children Act (1975). Pub. L. No. 94-142.

Flanagan, D. P. \& Alfonso, V. C. (2018). Essentials of specific learning disability identification ( $2^{\text {nd }}$ ed.). Wiley.

Flanagan, D. P., Ortiz, S. O. \& Alfonso, V. C. (2013). Essentials of cross battery assessment (3rd ed.). Wiley.

Fletcher, J. M. (2012). Classification and identification of learning disabilities. In B. Wong \& D. L. Butler (Eds.), Learning about learning disabilities (pp. 1-26). Academic Press. http://dx.doi.org/10.1016/B978-0-12-388409-1.00001-1

Fletcher, J. M., \& Miciak, J. (2019). The identification of specific learning disabilities: A summary of research on best practices. Texas Center for Learning Disabilities.

Francis, D. J., Fletcher, J. M., Stuebing, K. K., Lyon, G. R., Shaywitz, B. A., \& Shaywitz, S. E. (2005). Psychometric approaches to the identification of LD: IQ and achievement scores are not sufficient. Journal of Learning Disabilities, 38, 98-108. doi:10.1177/00222194050380020101

Garcia-Perez, M. A., \& Nunez-Anton, V. (2003). Cellwise residual analysis in two-way contingency tables. Educational and psychological measurement, 63(5), 825-839. 
Gentrup, S., Lorenz, G., Kristen, C., \& Kogan, I. (2020). Self-fulfilling prophecies in the classroom: Teacher expectations, teacher feedback and student achievement. Learning and Instruction, 66, 101296. https://doi.org/10.1016/j.learninstruc.2019.101296

Higgins, E., Raskind, M., Goldberg, R., \& Herman, K. (2002). Stages of acceptance of a learning disability: The impact of labeling. Learning Disability Quarterly, 25(1), 3-18. doi:10.2307/1511187

Individuals with Disabilities Education Improvement Act (IDEA) of 2004, Pub. L. No. 108446,1118Stat. 2647; 2004 enacted H. R. 1350; 108 Enacted H. R. 1350. Final regulations implementing IDEA 2004 were published in the Federal Register, Monday, August 14, 2006, pp. 46540-46845.

Kranzler, J. H., Floyd, R. G., Benson, N., Zaboski, B., \& Thibodaux, L. (2016). Cross-battery Assessment pattern of strengths and weaknesses approach to the identification of specific learning disorders: Evidence-based practice or pseudoscience? International Journal of School \& Educational Psychology, 4, 146-157. doi:10.1080/21683603.2016.1192855

Levenson, N. (2012). Boosting the quality and efficiency of special education. Thomas B. Fordham Institute.

Lichtenstein, R. (2014). Best practices in identifying learning disabilities. In P. L. Harrison \& A. Thomas (Eds.), Best practices in school psychology: Data-based and collaborative decision making (pp.331-354). National Association of School Psychologists Publications.

Lockwood, A., Farmer, R., Bohan, K., Winans, S., \& Sealander, K. (2021). Academic achievement test use and assessment practices: A national survey of special education 
administrators. Journal of Psychoeducational Assessment.

doi.org/10.1177\%2F0734282920984290

Louisiana Department of Education. (2009). Bulletin 1508: Pupil appraisal handbook.

Maki, K. E., \& Adams, S. R. (2018). A current landscape of specific learning disability identification: Training, practices, and implications. Psychology in the Schools, 56(1), 1831. https://doi.org/10.1002/pits.22179

Maki, K. E., \& Adams, S. R. (2020). Specific learning disabilities identification: Do the identification methods and data matter?. Learning Disability Quarterly, 43(2), 63-74. https://doi.org/10.1177/0731948719826296

Maki, K. E., Burns, M. K., \& Sullivan, A. (2017). Learning disability identification consistency: The impact of methodology and student evaluation data. School Psychology Quarterly, 32(2), 254. https://doi.org/10.1037/spq0000165

Maki, K. E., Floyd, R. G., \& Roberson, T. (2015). State learning disability eligibility criteria: A comprehensive review. School Psychology Quarterly, 30(4), 457-469. https://doi.org/10.1037/spq0000109

Miciak, J. \& Fletcher, J. M. (2019). The identification of learning disabilities: PSW versus RtI methods. In M. K. Burns (ed.), Introduction to school psychology: Controversies and current practice. pp. 336-359. Oxford University Press.

Miciak, J., Fletcher, J. M., Stuebing, K. K., Vaughn, S., \& Tolar, T. D. (2014). Patterns of cognitive strengths and weaknesses: Identification rates, agreement, and validity for learning disabilities identification. School Psychology Quarterly, 29, 21-37. doi:10.1037/spq0000037

Miciak, J., Taylor, W. P., Denton, C. A., \& Fletcher, J. M. (2015). The effect of achievement test 
selection on identification of learning disabilities within a patterns of strengths and weaknesses framework. School Psychology Quarterly, 30, 321-334. doi:10.1037/spq0000091

Miciak, J., Williams, J. L., Taylor, W. P., Cirino, P. T., Fletcher, J. M., \& Vaughn, S. (2016). Do processing patterns of strengths and weaknesses predict differential treatment response? Journal of Educational Psychology, 108, 898. doi:10.1037/edu0000096

National Association of School Psychologists (NASP). (2017). Shortages in school psychology: Challenges to meeting the growing needs of US students and schools. NASP

National Center for Education Statistics. (2017). Enrollment in public elementary and secondary schools, by region, state, and jurisdiction: Selected years, fall 1990 through fall 2029. https://nces.ed.gov/programs/digest/d19/tables/dt19_203.20.asp

National Center for Education Statistics. (2019, June 6). The condition of education: Students w/disabilities. https://nces.ed.gov/programs/coe/indicator_cgg.asp

National Center for Education Statistics. (2020, June 6). Search for Public Schools. https://nces.ed.gov/ccd/schoolsearch/

Scariano, S. M., \& Davenport, J. M. (1987). The effects of violations of independence assumptions in the one-way ANOVA. The American Statistician, 41(2), 123-129.

Schultz, E. K., \& Stephens, T. L. (2015). Core-selective evaluation process: An efficient \& comprehensive approach to identify students with SLD using the WJ IV. Dialog: Journal of the Texas Educational Diagnosticians Association, 44(2).

Stuebing, K. K., Fletcher, J. M., Branum-Martin, L., \& Francis, D. J. (2012). Evaluation of the technical adequacy of three methods for identifying specific learning disabilities based on 
cognitive discrepancies. School Psychology Review, 41, 3-22.

https://doi.org/10.1080/02796015.2012.12087373

Vaughn, S., \& Fuchs, L. S. (2003). Redefining learning disabilities as inadequate response to instruction: The promise and potential problems. Learning Disabilities Research \& Practice, 18, 137-146. doi:10.1111/1540-5826.00070

Vellutino, F. R., Scanlon, D. M., Small, S., \& Fanuele, D. P. (2006). Response to intervention as a vehicle for distinguishing between children with and without reading disabilities:

Evidence for the role of kindergarten and first-grade interventions. Journal of Learning Disabilities, 39, 157-169. https/doi.org/10.1177/00222194060390020401 
Table 1 Demographic Variables

\begin{tabular}{|c|c|c|}
\hline Respondent Characteristics & $n$ & $\%$ \\
\hline \multicolumn{3}{|l|}{ Gender } \\
\hline Female & 576 & 79.9 \\
\hline Male & 141 & 19.6 \\
\hline Prefer not to say & 4 & 0.6 \\
\hline \multicolumn{3}{|l|}{ District Type } \\
\hline Traditional/regular school district & 687 & 93.9 \\
\hline Regional district & 7 & 1.0 \\
\hline State district & 9 & 1.2 \\
\hline Charter school & 10 & 1.4 \\
\hline Component school district & 1 & 0.1 \\
\hline Special Education Cooperative & 13 & 1.8 \\
\hline Other & 4 & 0.6 \\
\hline \multicolumn{3}{|l|}{ Locale } \\
\hline Urban & 59 & 8.2 \\
\hline Suburban & 224 & 31.0 \\
\hline Large town & 160 & 22.2 \\
\hline Town & 236 & 32.7 \\
\hline Rural & 43 & 6.0 \\
\hline \multicolumn{3}{|l|}{ Racial/Ethnic Identity } \\
\hline White (non-Hispanic) & 636 & 88.1 \\
\hline Hispanic/Latino & 25 & 3.5 \\
\hline Black/African American (non-Hispanic) & 32 & 4.4 \\
\hline Native American/American Indian & 1 & 0.1 \\
\hline Asian & 7 & 1.0 \\
\hline Multiracial & 1 & 0.1 \\
\hline Native Hawaiian or Other Pacific Islander & 2 & 0.3 \\
\hline Middle Eastern or North African & 1 & 0.1 \\
\hline Some other race, ethnicity, or origin & 2 & 0.3 \\
\hline Prefer not to say & 15 & 2.1 \\
\hline \multicolumn{3}{|l|}{ Region } \\
\hline West & 129 & 17.8 \\
\hline Midwest & 184 & 25.4 \\
\hline South & 265 & 36.6 \\
\hline Northeast & 147 & 20.3 \\
\hline \multicolumn{3}{|l|}{ Highest educational level } \\
\hline Bachelors & 4 & 0.6 \\
\hline Masters & 320 & 44.3 \\
\hline
\end{tabular}


SLD IDENTIFICATION AND ASSESSMENT PRACTICES

$\begin{array}{lcc}\text { Specialists } & 174 & 24.1 \\ \text { Doctorate } & 197 & 27.2 \\ \text { Other } & 28 & 3.9\end{array}$

Years working in education

2-4

5-9

10-14

15-19

20-24

25-29

$30-34$

35-39

$40-44$

$45-49$

50-53

Years in current district

$\begin{array}{lcc}1-4 & 225 & 31.3 \\ 5-9 & 135 & 18.8 \\ 10-14 & 109 & 15.2 \\ 15-19 & 98 & 13.6 \\ 20-24 & 77 & 10.7 \\ 25-29 & 36 & 5.0 \\ 30-34 & 31 & 4.3 \\ 35-39 & 4 & 0.5 \\ 40-46 & 4 & 0.5\end{array}$

Note. Locales were based on U.S. census definitions and were defined on the survey as: Urban $=$ city with population greater than 250,000, Suburban $=$ included in an urban metro area but not within city limits. Large town = population greater than 25,000 and not part of a greater metro area, Town $=$ population between 2,500 and 24,999, and Rural = rural or town with a population of less than 2,500. 


\section{Table 2}

Primary SLD Identification Method by Region

\begin{tabular}{|c|c|c|c|c|c|c|}
\hline \multirow[b]{3}{*}{ Region } & RtI & AAD & PSW & $\mathrm{RtI}$ and $\mathrm{AAD}$ & RtI and PSW & \multirow{3}{*}{$\begin{array}{l}\text { Total } \\
\qquad N\end{array}$} \\
\hline & $n(\%)$ & $n(\%)$ & $n(\%)$ & $n(\%)$ & $n(\%)$ & \\
\hline & Adj. Res. & Adj. Res. & Adj. Res. & Adj. Res. & Adj. Res. & \\
\hline \multirow[t]{2}{*}{ West } & $10(8.0)$ & $65(52.0)$ & $20(16.0)$ & $18(14.4)$ & $12(9.6)$ & \multirow[t]{2}{*}{125} \\
\hline & $-3.6^{*}$ & $6.0 *$ & -1.3 & -0.4 & -1.8 & \\
\hline \multirow[t]{2}{*}{ Midwest } & $56(31.1)$ & $32(17.8)$ & $41(22.8)$ & $18(10.0)$ & $33(18.3)$ & \multirow[t]{2}{*}{180} \\
\hline & $4.4 *$ & $-4.1 *$ & 1.0 & -2.3 & 1.5 & \\
\hline \multirow[t]{2}{*}{ South } & $53(20.2)$ & $56(21.3)$ & $74(28.1)$ & $41(15.6)$ & $39(14.8)$ & \multirow[t]{2}{*}{263} \\
\hline & 0.2 & $-3.8 *$ & $4.0 *$ & 0.1 & 0.0 & \\
\hline \multirow[t]{2}{*}{ North East } & $22(15.2)$ & $59(40.7)$ & $9(6.2)$ & $33(22.8)$ & $22(15.2)$ & \multirow[t]{2}{*}{145} \\
\hline & -1.6 & $3.2 *$ & $-4.7 *$ & 2.7 & 0.1 & \\
\hline Overall Sample & $141(19.8)$ & $212(29.0)$ & $144(20.2)$ & $110(15.4)$ & 106 (14.9) & 713 \\
\hline
\end{tabular}

Note $\cdot x^{2}(12, n=713)=100.01, p<.001$, Cramer's $V=.216 .{ }^{*}$ Significant after Bonferroni-correction. 
Primary SLD Identification Method by Locale

\begin{tabular}{|c|c|c|c|c|c|c|}
\hline \multirow[b]{3}{*}{ Locale } & RtI & AAD & PSW & $\mathrm{RtI}$ and $\mathrm{AAD}$ & RtI and PSW & \multirow[b]{2}{*}{ Total } \\
\hline & $n(\%)$ & $n(\%)$ & $n(\%)$ & $n(\%)$ & $n(\%)$ & \\
\hline & Adj. Res. & Adj. Res. & Adj. Res. & Adj. Res. & Adj. Res. & $N$ \\
\hline \multirow[t]{2}{*}{ Urban } & $7(12.1)$ & $18(31.0)$ & $15(25.9)$ & $12(20.7)$ & $6(10.3)$ & 58 \\
\hline & -1.5 & 0.2 & 1.1 & 1.2 & -1.0 & \\
\hline \multirow[t]{2}{*}{ Suburban } & $50(22.7)$ & $66(30.0)$ & $47(21.4)$ & $30(13.6)$ & $27(12.3)$ & 220 \\
\hline & 1.4 & 0.1 & 0.5 & -0.8 & -1.3 & \\
\hline \multirow[t]{2}{*}{ Large town } & $27(17.4)$ & $46(29.7)$ & $30(19.4)$ & $28(18.1)$ & $24(15.5)$ & 155 \\
\hline & -0.8 & -0.1 & -0.3 & 1.1 & 0.2 & \\
\hline \multirow[t]{2}{*}{ Town } & 46 (19.6) & $68(28.9)$ & $46(19.6)$ & $31(13.2)$ & $44(18.7)$ & 235 \\
\hline & -0.1 & -0.4 & -0.3 & -1.1 & 2.0 & \\
\hline \multirow[t]{2}{*}{ Rural } & $10(23.8)$ & $14(33.3)$ & $6(14.3)$ & 7 (16.7) & $5(11.9)$ & 42 \\
\hline & 0.7 & 0.5 & -1.0 & 0.3 & -0.6 & \\
\hline Overall Sample & $140(19.7)$ & $212(29.9)$ & $144(20.3)$ & $108(15.2)$ & $106(14.9)$ & 710 \\
\hline
\end{tabular}

Note $x^{2}(16, n=710)=13.09, p=.67$. Cramer's $V=.067$. Locales were based on U.S. census definitions and were defined on the survey as: Urban $=$ city with population greater than 250,000 , Suburban $=$ included in an urban metro area but not within city limits. Large town $=$ population greater than 25,000 and not part of a greater metro area, Town = population between 2,500 and 24,999, and Rural = rural or town with a population of less than 2,5000. 


\section{Table 4}

Primary SLD Identification Method by Test Administrator Profession

\begin{tabular}{|c|c|c|c|c|c|c|}
\hline \multirow[b]{3}{*}{ Profession } & RtI & $\mathrm{AAD}$ & PSW & $\mathrm{RtI}$ and $\mathrm{AAD}$ & RtI and PSW & \multirow{3}{*}{$\begin{array}{l}\text { Total } \\
\quad N\end{array}$} \\
\hline & $n(\%)$ & $n(\%)$ & $n(\%)$ & $n(\%)$ & $n(\%)$ & \\
\hline & Adj. Res. & Adj. Res. & Adj. Res. & Adj. Res. & Adj. Res. & \\
\hline \multirow[t]{2}{*}{ Special Education Teacher } & $37(19.1)$ & $75(38.7)$ & $24(12.4)$ & $30(15.5)$ & $28(14.4)$ & \multirow[t]{2}{*}{194} \\
\hline & -0.3 & $3.2 *$ & $-3.1 *$ & 0.0 & -0.2 & \\
\hline \multirow[t]{2}{*}{ School Psychologist } & $88(24.7)$ & $90(25.3)$ & $60(16.9)$ & $59(16.6)$ & $59(16.6)$ & \multirow[t]{2}{*}{356} \\
\hline & $3.3 *$ & -2.6 & -2.2 & 0.8 & 1.3 & \\
\hline \multirow[t]{2}{*}{ Educational Diagnostician } & $12(11.3)$ & $22(20.8)$ & $50(47.2)$ & $5(4.7)$ & $17(16.0)$ & \multirow[t]{2}{*}{106} \\
\hline & -2.4 & -2.2 & $7.5^{*}$ & $-3.3^{*}$ & 0.4 & \\
\hline \multirow[t]{2}{*}{ Other } & $4(7.1)$ & $25(44.6)$ & $9(16.1)$ & $16(28.6)$ & $2(3.6)$ & \multirow[t]{2}{*}{56} \\
\hline & -2.5 & 2.5 & -0.8 & 2.8 & -2.5 & \\
\hline Overall Sample & $141(19.8)$ & $212(29.8)$ & $143(20.1)$ & $110(15.4)$ & $106(14.9)$ & 712 \\
\hline
\end{tabular}

Note $\cdot x^{2}(12, n=712)=94.21, p<.001$, Cramer's $V=.210 . *$ Significant after Bonferroni-correction. 


\section{Table 5}

Primary SLD Identification Method by CBM usage

\begin{tabular}{lccc}
\hline & Yes & No & \multirow{2}{*}{ Overall Sample } \\
\cline { 2 - 3 } Method & $n(\%)$ & $n(\%)$ & $n(\%)$ \\
\cline { 2 - 3 } RtI & Adj. Res. & Adj. Res. & $138(19.9)$ \\
AAD & $126(91.3)$ & $12(8.7)$ & $205(29.5)$ \\
PSW & $2.7^{*}$ & $-2.7 *$ & $140(20.2)$ \\
RtI and AAD & $165(80.5)$ & $40(19.5)$ & $107(15.4)$ \\
RTI and PSW & -1.6 & 1.6 & $104(15.0)$ \\
Total $(N)$ & $107(76.4)$ & $33(23.6)$ & $2.7 *$ \\
\hline
\end{tabular}

Note. $x^{2}(4, n=694)=15.464, p<.005$, Cramer's $V=.149$. *Significant after Bonferroni-correction. 